\title{
DOI: http://doi.org/10.21698/simi.2017.0023 \\ STUDY ON ELECTROMAGNETIC WAVES AND THEIR EFFECT ON THE ENVIRONMENT AND POPULATION HEALTH
}

\author{
Mihai Bratu, Tanase Gheorghita, Danciulescu Valeriu, Ileana Nicolescu, Mihaela Petrescu \\ National Research and Development Institute for Industrial Ecology ECOIND, 71-73 Drumul \\ Podul Dambovitei, 060652, Bucharest, Romania,cmm_bratu@yahoo.com
}

\begin{abstract}
Electromagnetic fields (EMF) are a combination of invisible electrical and magnetic fields of force. EMF is present in all places where electricity is used and surrounds every charged electric object. The impact of the electromagnetic field on the environment and people's health has begun to awaken more and more the interest of research in this field. This is due to the widespread development of various devices that emit electromagnetic waves on different frequencies. This paper presents comparative studies on the level of electromagnetic waves. Determinations have been made both at source so as to highlight the dispersion of electromagnetic waves and their effect on the population in the studied area.
\end{abstract}

Keywords: electromagnetic field, electromagnetic waves, frequency, source

\section{Introduction}

The exposure of live organisms to electromagnetic field generating equipment and devices has steadily increased in recent years, given the increasing number and power of these facilities and devices. The human body has developed different adaptation mechanisms, but exposure to high radiation and long periods of time may pose a health hazard. Many people claim sensitivities such as headaches, insomnia, depression or lack of concentration due to the influence of electromagnetic radiation on the human body. Many research shows that exposure to electromagnetic fields does not pose a health risk, but there are still many controversies and limitations in knowing the long-term negative influences. (Magureanu 2003; Marin et al. 2017; Marin et al. 2015).

What we can say with certainty is that we live in a radiation environment. Thus, there is a natural level of radiation but also secondary and artificial sources with the same effect on health. Knowing these effects is absolutely necessary for the development of biological protection conditions. The probability of occurrence of any effect is in direct correlation with the radiation dose received (Mai 2011; Bucur et al. 2016; Bucur et al. 2017) .

Electromagnetic waves are transversal waves with two components: a magnetic component and an electrical component, the electric and magnetic vectors being perpendicular to each other and to the propagation direction.

Non-ionizing radiation covers the visible spectrum up to very low-frequency radiation (ELF- Extremely Low Frequency) such as waves produced by base stations of mobile telephony, are non-ionizing radiation (Zagar et al. 2014; Albert et al. 2005; Bernhardt 1992). 
It is recognized that exposure to non-ionised electromagnetic fields in the $300 \mathrm{MHz}$ to $300 \mathrm{GHz}$ range is unfavorable to human health. (Vijayalaxmi \& Scarfi 2014; Heynick et al. 2003; Meltz 2003; Vijayalaxmi \& Prihoda 2008; Verscha 2009).

The data presented in the paper are part of a larger study dedicated to assessing the level of electromagnetic radiation emissions and the possible effect on health and it includes the results of the tests performed in two areas characterized by two distinct sources emitting electromagnetic radiation on different frequencies.

\section{Experimental}

\section{Location}

The tests were conducted in two locations located near electromagnetic radiation sources: a GSM antenna Fig. 1-a and electric power transformer station Fig. 1-b located in residential areas of Bucharest. The determinations for the electromagnetic radiation level were made near the source for the case of the source 1- Fig. 1-a and also for the case of the source 2 - Fig. 1-b the determinations were made in two directions: magnetic field determination in the direction (A) without attenuating wall and magnetic field determination in direction (b) with attenuating wall as shown in the sketch of Fig. 2.

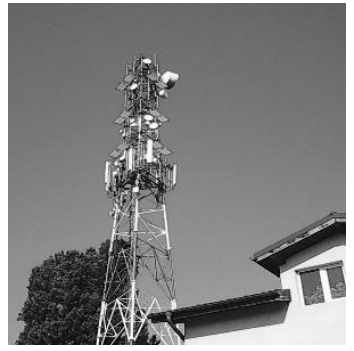

(a)

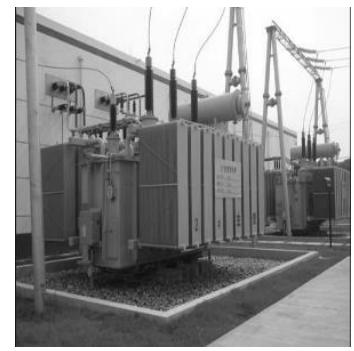

(b)

Figure 1. The two sources for which electromagnetic radiation determinations have been made

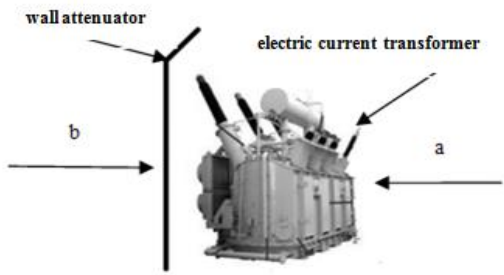

Figure 2. Outline of magnetic field determinations

Measured methods, equipment and indicators

In order to determine the level of electromagnetic radiation measurements were carried out respecting the requirements of the regulations and the standards in force (Romanian standard 50364:2010), (Romanian standard 50385:2003) (Government 
decision 520/2016), (Government decision 1136/2006), (Government decision 1193/2006).

In order to assess the exposure of the human body to electromagnetic radiation, the most relevant parameters are the intensity and the power of the radiation. Exposure coming from multiple sources, power will be a result of the powers of the fields that propagate in several directions. To measure the power of the electromagnetic field, SPECTRAN HF 60105 was used to measure high frequency electromagnetic radiation (GSM mobile antenna) and SPECTRAN NF 5035 for measuring low frequency electromagnetic radiation (Figure 3 ) with specific detection sensors.

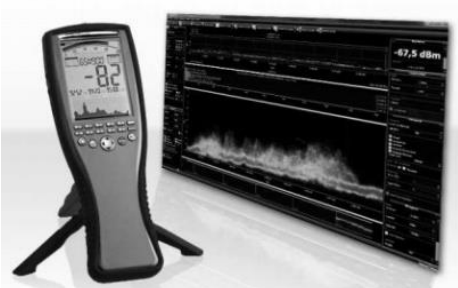

Figure 3. SPECTRAN NF 5035 Analyzer for Electromagnetic Wave Power Measurement

According to the relation (1) the amplitude of the electric field of incidence is the result of the vector composition on the three axes (Figure 4):

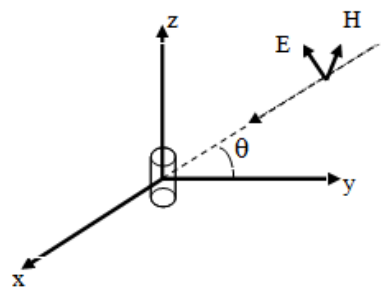

Figure 4. Sketch of the triaxial sensor of the SPECTRAL analyzer

$$
|E|=\left(E^{2} x+E_{y}^{2}+E_{z}^{2}\right)^{1 / 2}
$$

$E$ is the amplitude of the electric field of incidence and $\theta$ is the angle between the sensor axis and the electric field direction, the detected signal is proportional to $|\mathrm{E}|$ $\cos \theta$. The overall amplitude of the field is expressed as:

$$
|\mathrm{H}|=\left(\mathrm{H}^{2}{ }_{\mathrm{x}}+\mathrm{H}^{2}{ }_{\mathrm{y}}+\mathrm{H}^{2}{ }_{\mathrm{z}}\right)^{1 / 2}
$$

In the case of the magnetic field, it is characterized by two parameters: the field strength $(\mathrm{H})$, which is measured in $\mathrm{A} / \mathrm{m}$ and the flux density $(\mathrm{B})$, which is measured in gauss $(\mathrm{G})$ and tesla $(\mathrm{T})$.

$$
1 \mathrm{~T}=1(\mathrm{~V} * \mathrm{~s}) / \mathrm{m}^{2}
$$


( $\mathrm{V}=$ volt, $\mathrm{s}=$ second, $\mathrm{m}=$ meter $),(5$ October 2011)

Measurements were made under the following conditions: the $200 \mathrm{kHz}$ resolution band; Scanning time $250 \mathrm{~ms} ; 1 \mathrm{MHz}$ frequency step; Detector distance from the reference plane $1.5 \mathrm{~m}$. Table 1 lists the magnitude reference values for the electromagnetic field in the frequency range $0-300 \mathrm{~Hz}$ considered dangerous for the human body.

Table 1. Reference levels for parameters characteristic of electromagnetic fields

\begin{tabular}{ccccc}
\hline Frequency range & $\begin{array}{c}\text { Intensity electric } \\
\text { field } \\
\mathrm{E}(\mathrm{V} / \mathrm{m})\end{array}$ & $\begin{array}{c}\text { Intensity magnetic } \\
\text { field } \\
\mathrm{H}(\mathrm{A} / \mathrm{m})\end{array}$ & $\begin{array}{c}\text { Magnetic } \\
\text { induction } \\
\mathrm{B}(\mu \mathrm{T})\end{array}$ & $\begin{array}{c}\text { Power Density } \\
\text { for Equivalent plane } \\
\text { wave Seq(W/m2) }\end{array}$ \\
\hline $0-1 \mathrm{~Hz}$ & - & $3,2^{*} 10^{4}$ & $4 * 10^{4}$ & - \\
$1-8 \mathrm{~Hz}$ & 10000 & $3,2 * 10^{4} / \mathrm{f}^{2}$ & $4 * 10^{4} / \mathrm{f}^{2}$ & - \\
$8-25 \mathrm{~Hz}$ & 10000 & $4000 / \mathrm{f}$ & $5000 / \mathrm{f}$ & - \\
$0,025-0,8 \mathrm{kHz}$ & $250 / \mathrm{f}$ & $4 / \mathrm{f}$ & $5 / \mathrm{f}$ & - \\
$0,8-3 \mathrm{kHz}$ & $250 / \mathrm{f}$ & 5 & 6,25 & - \\
$3-150 \mathrm{kHz}$ & 87 & 5 & 6,25 & - \\
$0,15-1 \mathrm{MHz}$ & 87 & $0,73 / \mathrm{f}$ & $0,92 / \mathrm{f}$ & - \\
$1-10 \mathrm{MHz}$ & $87 / \mathrm{f}$ & $0,73 / \mathrm{f}$ & $0,92 / \mathrm{f}$ & - \\
$10-400 \mathrm{MHz}$ & 28 & 0,073 & 0,092 & 2 \\
$400-2.000 \mathrm{MHz}$ & $3 \mathrm{f}^{2}$ & $0,008 \mathrm{f}^{2}$ & $0,01 \mathrm{f}^{2}$ & $\mathrm{f} / 40$ \\
$2-300 \mathrm{GHz}$ & 61 & 0,16 & 0,20 & 10 \\
\hline
\end{tabular}

$* \mathrm{f}-$ frequency, $\mathrm{Hz}$

\section{Results and Discussion}

The values of the electromagnetic field measurements for the source 1, respectively the mobile antenna, are shown in the diagram in Fig. 5-a and 5-b. Characteristics: tower $20 \mathrm{~m}$ height and antenna power $60 \mathrm{~W}$. Measured parameters: electric field intensity $\mathrm{E}(\mathrm{V} / \mathrm{m})$ and intensity of magnetic field $\mathrm{H}(\mathrm{A} / \mathrm{m})$. Also the maximum peak values for the two measured parameters are presented. Fig. 4a shows the intensity variation of the electric field, E function of the frequency, measured at the source. A maximum value determined for the field strength of $99.30 \mathrm{mV} / \mathrm{m}$ at a frequency of $953.5 \mathrm{~Hz}$ is observed. Calculating the reference level for the $\mathrm{f}=900 \mathrm{~Hz}$ frequency according to the relationship in Table 1 gives the value of $41.25 \mathrm{~V} \mathrm{~m}$.

Fig. 4-b shows the intensity variation of the magnetic field $\mathrm{H}$. In this diagram, a maximum magnetic field strength of $268.9 \mu \mathrm{A} / \mathrm{m}$ is observed. Calculating the reference level according to Table 1 , a value of $0.111 \mathrm{~A} / \mathrm{m}$ is obtained as the magnetic field exposure limit value. Thus, the values determined for the field strength and the magnetic field strength measured at the GSM antenna source are below the reference level calculated at the $900 \mathrm{~Hz}$ frequency according to Table 1 . For source 2 determinations for induction of magnetic field are shown in Fig. 6-a without attenuating wall and Fig. 6-b with attenuating wall. Also in Fig. 7-a and 7-b the magnetic field dispersion for the studied source 2 is presented. 


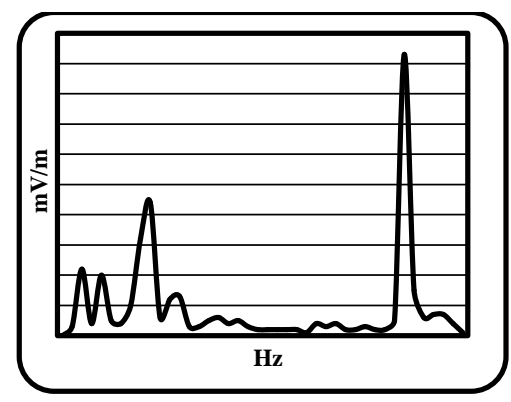

(a)

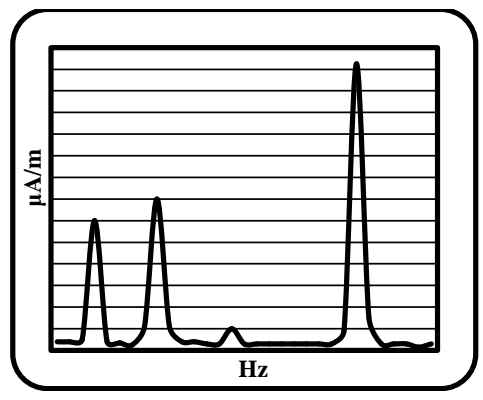

(b)

Figure 5. Variation of the intensity electric field (a) and intensity magnetic field (b) at the GSM antenna

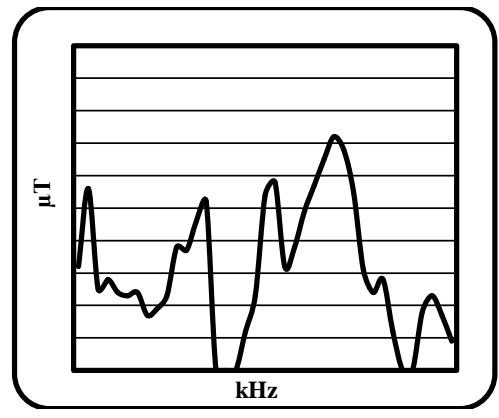

(a)

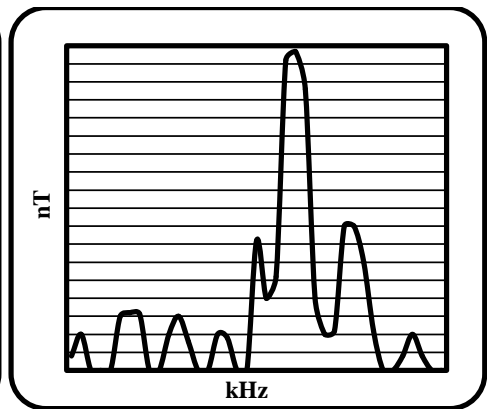

(b)

Figure 6. Frequency variation of magnetic field intensity for the two situations at source 2 without attenuating wall (a); with attenuating wall (b)

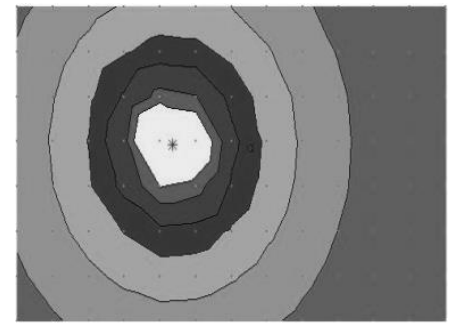

(a)

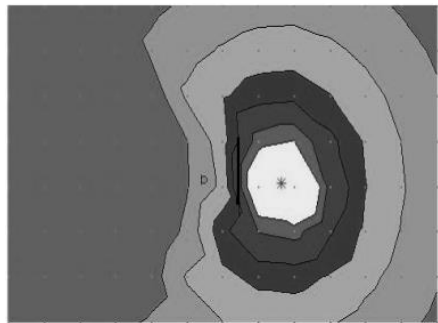

(b)

Figure 7. Mathematical modeling of the magnetic field dispersion according to frequency for the two situations at source 2 without attenuating wall (a); with attenuating wall (b)

It is observed that in the case of determining the induction of the magnetic field at the electric transformer source, for the case (a) without attenuating wall a maximum value 
of $7.2 \mu \mathrm{T}$ was obtained at a frequency of $50 \mathrm{kHz}$ so it is a value that exceeds the level for the $3-150 \mathrm{kHz}$ range according to Table 1 . When determining the attenuator wall point (b), a magnetic field inductance value of $442 \mathrm{nT}$ resulted in a value below the reference level according to Table 1 .

\section{Conclusions}

Today's world is subject to an ocean of electromagnetic waves due to a large number of sources of radiation both in and outside homes. The sources studied in this GSM antenna paper and electric current transformer are sources that the electromagnetic radiation emitted may affect the health of the people in the area. Thus, in the case of the GSM antenna, measurements were made to determine the level of electromagnetic waves at the base of the source. The intensity of the field and the intensity of the magnetic field were determined. Also, for source 2, the magnetic field intensity was measured in two directions with no attenuating wall and attenuator wall and the results were compared with the reference level presented in Table 1 and calculated at the frequency at which the determinations were made. Thus, for the source 1 for the 2 parameters determined, values below the reference level calculated according to Table 1 were obtained since the GSM antennas are mounted at a height of about $20 \mathrm{~m}$ so that it can not affect the population due to the electromagnetic radiation. In the case of source 2, according to the diagrams in Fig. 6, a high high level of $7.2 \mu \mathrm{T}$ at a frequency of $50 \mathrm{kHz}$ exceeding the reference level in Table 1 for the case of attenuating wall determinations is observed. Measurement in the attenuator side caused $442 \mathrm{nT}$ values to be below the reference level according to Table 1 so that it is useful to construct this attenuating wall between the power transformer and the living quarters.

\section{Acknowledgements}

The authors are grateful for the financial support of project PN 16250212 (Contract no.38N/2016).

\section{References}

Albert, N, Sherif, MF, Papadopoulos, NJ, Slaby, FJ \& Monahan, J 2005, 'Effect of nonionizing radiation on the purkinje cells of the rat cerebellum', Bioelectromagnetics, vol. 2, pp. $247-257$.

Bernhardt, JH 1992, 'Non-ionizing radiation safety: radiofrequency radiation, electric and magnetic fields', Physics in medicine and biology, no.37, pp.807-844.

Bucur, E, Danet, AF, Lehr, CB, Lehr, E \&Vasile, A 2016, 'Indoor air quality assessment in the Romanian national aviation museum', Revista de Chimie (Bucharest), vol. 67, no. 8, pp. 1421-1426.

Bucur, E, Danet, AF , Lehr CB, Lehr, E \& Nita-Lazar, M 2017, 'Binary logistic regression - instrument for assessing museum indoor air impact on exhibits' Journal of the Air\&Waste Management Association, vol.67, no. 4, pp. 391-401.

Heynick, LN, Johnston, SA \& Mason, PA 2003, 'Radio frequency electromagnetic fields: cancer, mutagenesis and genotoxicity', Bioelectromagnetics, no.6, pp. 74-100.

Government decision 520/2016 - 'Minimum safety and health requirements for workers' exposure to risks from electromagnetic fields. 
Government decision 1136/2006 - 'Minimum safety and health requirements for workers' exposure to risks from electromagnetic fields.

Government decision 1193/2006 - 'Rule to Limit Population Exposure to Electromagnetic Fields'.

https://gabionescu.wordpress.com/2011/05/20/cate-ceva-despre-radiatii/[16 Mai 2017].

http://camp-electromagnetic.infarom.ro/surse.html [2011].

Magureanu, G 2003, 'Field electrical to the ground - characteristics and measurement problems', Proceedings of The 5th International Power Systems Conference, Bucharest, pp. 367-372.

Marin, NM , Vasile, GG, Simion, M , Pascu, LF \& Lehr, CB 2017, 'Rapid method for evaluation of metallic mobile fraction from sewage sludge samples', Scientific Studies and Research Chemistry and Chemical Engineering, Biotechnologies, Food Industry, vol. 18, no. 1, pp. 45 -52.

Marin, NM , Vasile, GG, Petre, J \& Cruceru, LV 2015, 'Improved aqua regia metal extraction using a loam soil CRM-ERC-CC141 and a performant microwave oven', International symposium The Environment and the Industry, National Research and Development Institute for Industrial Ecology ECOIND, Bucharest, pp. 215-219.

Meltz, ML 2003, 'Radiofrequencyexposure and mammalian cell toxicity, genotoxocity, and transformation', Bioelectromagnetics, no. 6, pp. 196-213.

Zagar, GR, Matornei, M, Darabont, A, Mot, A \& Zagar, CR, Electric field. Health Effects, old.protectiamuncii.ro/ro/good_practice/campul-elecromagnetic.html [11 Mai 2017].

Romanian standard 50364:2010 - Limitation of human exposure to electromagnetic fields generated by equipment operating in the frequency range from $0 \mathrm{~Hz}$ to $300 \mathrm{GHz}$, used for Electronic Object Surveillance (EAS), Radio Frequency Identification (RFID) and similar applications.

Romanian standard 50385:2003- Product standard for demonstration of compliance of base stations and stationary terminals for radio telecommunication systems with basic restrictions or reference levels related to human exposure to radio frequency electromagnetic fields $(110 \mathrm{MHz}$... 40GHz) -population in general.

Verscha, L 2009, 'Genetic damage in subjects exposed to radiofrequency radiation', Mutation resarch, no 681, pp 259-270.

Vijayalaxmi, Y \& Scarfi, MR 2014, 'Adaptive response in mammalian cells exposed to non - ionizing radiofrequency fields: A review and gaps in knowledge', Mutation research, no. 760, pp 36-45.

Vijayalaxmi, Y \& Prihoda, TJ 2008, 'Genetic damage in mammalian somatic cells exposed to radiofrequency radiation: a meta-analys of data from 63 publications (1990-2005)', Radiation research, no. 169, pp 651-574. 